University of Nebraska - Lincoln

DigitalCommons@University of Nebraska - Lincoln

Sociology Department, Faculty Publications

Sociology, Department of

2012

\title{
Exploring the Relationships of Perceived Discrimination, Anger, and Aggression among North American Indigenous Adolescents
}

Kelley J. Sittner Hartshorn

University of Nebraska-Lincoln, kelley.sittner@okstate.edu

Les B. Whitbeck

University of Nebraska-Lincoln, Iwhitbeck2@unl.edu

Dan R. Hoyt

University of Nebraska-Lincoln, dhoyt2@unl.edu

Follow this and additional works at: https://digitalcommons.unl.edu/sociologyfacpub

Part of the Sociology Commons

Sittner Hartshorn, Kelley J.; Whitbeck, Les B.; and Hoyt, Dan R., "Exploring the Relationships of Perceived Discrimination, Anger, and Aggression among North American Indigenous Adolescents" (2012). Sociology Department, Faculty Publications. 177.

https://digitalcommons.unl.edu/sociologyfacpub/177

This Article is brought to you for free and open access by the Sociology, Department of at DigitalCommons@University of Nebraska - Lincoln. It has been accepted for inclusion in Sociology Department, Faculty Publications by an authorized administrator of DigitalCommons@University of Nebraska - Lincoln. 


\title{
Exploring the Relationships of Perceived Discrimination, Anger, and Aggression among North American Indigenous Adolescents
}

\author{
Kelley J. Sittner Hartshorn, Les B. Whitbeck, and Dan R. Hoyt \\ University of Nebraska-Lincoln, Lincoln, NE, USA \\ Corresponding author - Kelley J. Sittner Hartshorn, University of Nebraska- Lincoln, \\ Department of Sociology, 217 Benton Hall, Lincoln, NE 68588, USA; email khartshorn2@unl.edu
}

\begin{abstract}
A growing body of research has documented associations between discrimination, anger, and delinquency, but the exact nature of these associations remains unclear. Specifically, do aggressive behaviors emerge over time as a consequence of perceived discrimination and anger? Or do adolescents who engage in aggressive behavior perceive that they are being discriminated against and become angry? We use autoregressive cross-lagged path analysis on a sample of 692 Indigenous adolescents (mean age $=12$ years) from the Northern Midwest and Canada to answer these research questions. Results showed that the direction of effects went only one way; both perceived discrimination and anger were significantly associated with subsequent aggression. Moreover, early discrimination and anger each had indirect effects on aggressive behavior three years later, and anger partially mediated the association between discrimination and aggression. Perceived discrimination is but one of many strains related to unequal social position that these Indigenous youth experience, and it has important implications for the proliferation of disparities in later life.
\end{abstract}

Keywords: adolescents, juvenile delinquency, perceived discrimination

Both perceived discrimination and aggression represent important yet under-researched problems for Indigenous communities. The scarcity of research is notable considering that discrimination has been identified as a culturally specific risk factor for Indigenous well-being (Whitbeck et al. 2001; Zimmerman et al. 1996). What we do know is that discrimination is a consistent correlate of several negative outcomes. Experiences with discrimination are positively associated with anger
(Mellor et al. 2009), depressive symptoms, and alcohol abuse among Indigenous adults (Whitbeck et al. 2004; Whitbeck, McMorris, et al. 2002). They are also associated with increased depressive symptoms, substance use, anger, suicide ideation, and problem behaviors among Indigenous adolescents (Walls et al. 2007; Whitbeck et al. 2001; Yoder et al. 2006).

North American Indigenous (American Indian, Alaska Native, Canadian First Nations) ad- 
olescents are overrepresented in violent crime statistics, including offending and victimization. Combined rates of violence, specifically homicide, suicide, and family violence, are higher for American Indians on reservations than for any other group in the United States (Bachman 1992), with similar patterns for Canadian Aboriginal people (Royal Commission on Aboriginal Peoples 1996). Violent victimization of American Indians occurs at a rate more than twice the national average (Perry 2004) and occurs across age groups, housing locations, and gender (Greenfeld and Smith 1999). Furthermore, American Indians are more likely than any other ethnic group to be victims of interracial violence, committed 60 percent of the time by white perpetrators (Perry 2004).

Most research treats perceived discrimination as an independent variable and finds it to be positively associated with a variety of negative outcomes for young people (e.g., Taylor and Turner 2002). Yet a smaller body of research indicates that for some young people, perceptions of discrimination may be outcomes of peer rejection (Patterson, DeBaryshe, and Ramsey 1989), hostile attribution biases (Crick and Dodge 1996), or misinterpreting the motives of others (Crocker et al. 1991). This research suggests aggressive behavior is positively associated with perceived discrimination. We know of no studies that have explicitly investigated the temporal association between discrimination and adolescent aggressive behavior, an oversight that may have important implications for prior research that assumed the direction of effects without testing them. Moreover, the primary emphasis of research on discrimination and aggressive or delinquent behavior has been on African American samples (e.g., Caldwell et al. 2004; Martin et al. 2011). Consequently, we know even less about the association between perceived discrimination and aggression among Indigenous adolescents.

In addition, anger has been identified as a correlate of aggression or delinquency (Agnew 1992; Camodeca and Goossens 2005) and perceived discrimination (Mellor et al. 2009; Whitbeck et al. 2001). It is generally treated as a precursor to aggression (Camodeca and Goossens 2005) and hypothesized to be an intervening variable between strain (i.e., perceived discrimination) and delinquency (Agnew 1992). Yet as with perceived discrimination and aggression, we are aware of no studies to date that have explicitly tested those assumptions for Indigenous adolescents.
In this article, we use autoregressive crosslagged path analysis with longitudinal data on 692 adolescents from the Upper Midwest and Canada to answer three research questions. First, does early aggression lead to perceived discrimination, or do perceptions of discrimination lead to aggressive behavior? Second, does aggressive behavior precede adolescent anger, or does anger lead to aggression? Third, does anger mediate the association between perceived discrimination and aggression over time?

\section{Aggression as an Outcome of Perceived Discrimination}

In general, perceived discrimination is widespread among people with disadvantaged social status (Kessler, Mickelson, and Williams 1999) and has adverse effects on health, mental health, and behavior across age groups (Taylor and Turner 2002; Thoits 2010; Whitbeck et al. 2001; Williams, Neighbors, and Jackson 2003). Stress process theory offers a useful lens through which to understand the effects of perceived discrimination: The surrounding social structure brings with it stressful experiences, which affect individual functioning (Pearlin 1999). Minority groups face disproportionately high numbers of chronic stressors, including poverty, discrimination, and family disruption (Williams, Takeuchi, and Adair 1992). Chronic stressors are those that occur continuously or so regularly in daily life as to be perceived as continuous by the individual (Wheaton 1994). Indeed, minority status itself can serve as a stressor (Meyer 1995; Vega and Rumbaut 1991). Pearlin (1999) argues that certain stressors such as status strain, which evolves out of an individual's unequal social position, and contextual strain, which arises from difficulties encountered in an individual's proximal environment, are persistent and chronic stressors because they are embedded in enduring social contexts.

According to stress theory, perceived discrimination impairs healthy functioning; in the case of the present study, it is associated with adolescent aggression. Delinquent behavior may serve as an adaptation to strain, an unconscious effort of young people to cope with the stress of perceived discrimination (Brezina 1996; Hoffmann 2010). In a study of American Indian youth by Whitbeck, Hoyt, et al. (2002), perceived discrimination was associated with being involved with a gang, which is 
perhaps a coping mechanism for marginalized minority youth. Repeat experiences with perceived discrimination over time may lead to an escalation in aggressive behaviors (Hoffmann and Cerbone 1999). As Indigenous adolescents expand their social worlds, particularly as they leave the relative protection of reservations/reserves, they are more likely to encounter discrimination and prejudice.

\section{Perceived Discrimination as an Outcome of Aggressive Behavior}

There is also evidence that perceived discrimination is an outcome, rather than a predictor, of aggressive behavior. Aggressive youth are more likely to be rejected by peer groups than are nonaggressive youth (Dodge et al. 2003; Patterson et al. 1989). Furthermore, antisocial behavior likely also leads to rejection by other social groups, especially for racial and ethnic minorities who face more prejudice and discrimination. Rejection may be viewed as unfair or unwarranted, leading to perceptions of discrimination. For example, in their study of children aged 9 to 12 years, Crick and Dodge (1996) noted that reactive aggressive children had more hostile attribution biases (assigning malicious intent to others) than other children, particularly in ambiguous situations wherein the intent of others was not clear. This situational ambiguity is particularly salient to the perceptions of those with stigmatized status regarding the motives of those with dominant status. Using a sample of black and white college students, Crocker and colleagues (1991) found that black students were more likely to attribute prejudiced motives to the negative reactions of white peers when they perceived race was an issue.

Taken together, this literature suggests that aggressive adolescents may have particular difficulty in correctly understanding the nuances of interactions, especially with others from different racial or ethnic groups. Because of these interactional difficulties, aggressive adolescents who are rejected by peer and other social groups may perceive the rejection is due to discrimination rather than to their own behavior. The question of temporal order becomes an important one given that aggressive behavior can escalate with rejection. Understanding the aggressive behavior-perceived discrimination relationship would inform prevention and intervention programming for aggressive Indigenous youth.
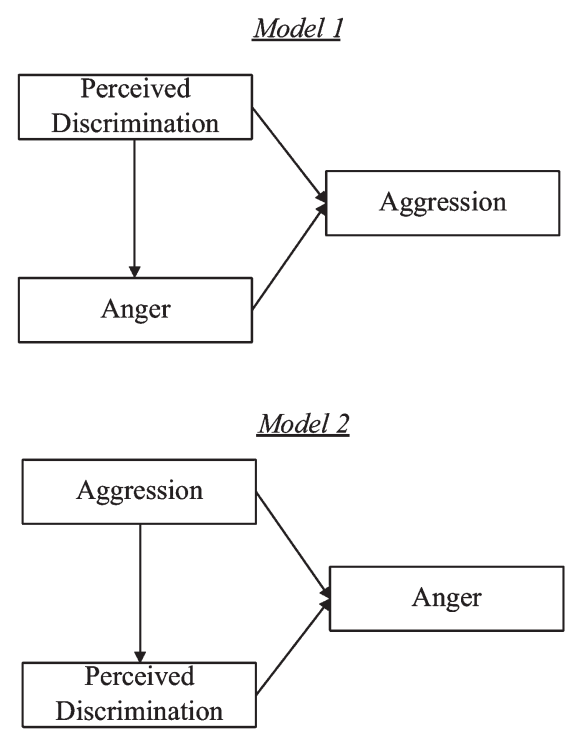

Figure 1. Graphic illustrations of conceptual models

\section{Associations between Anger, Aggression, and Perceived Discrimination}

Several causes of anger have been identified, such as someone or something that prevents one from attaining goals, creates or causes unpleasant events, or treats one unfairly (Berkowitz and Harmon- Jones 2004). Thus, it is easy to see anger as a natural emotional response to experiences of discrimination. For example, research with the Mapuche people of Chile found that experiences with discrimination led to feelings of anger as well as shame and feelings of powerlessness (Mellor et al. 2009). Anger also has been identified as an antecedent to aggression (Camodeca and Goossens 2005; Cornell, Peterson, and Richards 1999). Moreover, Agnew $(1992,2001)$ recognized anger as an intervening mechanism between stress and delinquent behavior in his General Strain Theory. The first model in Figure 1 provides a graphic illustration of this argument, which has been supported in the literature on delinquency. In their longitudinal study of high school youth, Aseltine, Gore, and Gordon (2000) found that family conflict and negative life events, both sources of strain, increased anger, which in turn increased aggressive delinquency. Although no research to date has looked specifically at discrimination, anger, and aggression 
among Indigenous youth, Whitbeck and colleagues (2001) found that perceived discrimination was associated with early-onset substance use via its effects on anger and delinquent behavior in a sample of American Indian middle school students.

On the other hand, anger may be fueled by having a negative appraisal of a situation or event (Smith et al. 1993), which casts doubt on the assumption that anger precedes aggression. Individuals with hostile attribution biases or who believe that reactions to their aggressive behaviors are prejudiced may become angry in response to perceived unfair treatment (see Figure 1, Model 2). Although anger has been conceptualized as an intervening variable in the stress-delinquency relationship (Agnew 1992, 2001), Agnew et al. (2002) described angry adolescents as more likely to perceive interactions as malicious and to have more intense emotional reactions to those events. Although there is more support in the literature for the first argument, the temporal order of aggression and anger remains ambiguous.

\section{Data and Method}

\section{Sample}

These data were collected as part of an ongoing longitudinal study designed in partnership with four U.S. reservations, four Canadian First Nations reserves, and a university-based research team. The reservations/reserves share a common cultural tradition and language with minor regional variations in dialects. The sample represents one of the most populous Indigenous cultures in the United States and Canada. As part of this partnership's confidentiality agreements, the names of the cultural group and participating reservations and reserves will not be identified. At each site, Tribal Council-appointed advisory boards were responsible for handling personnel difficulties, advising the research team on questionnaire development, and reviewing/approving reports and presentation proposals. All participating staff on the reservations and reserves (i.e., interviewers, site coordinators) were approved by advisory boards and were either enrolled tribal members or, in a very few cases, spouses of enrollees. Interviewers for this project were trained prior to each interview wave concerning methodological guidelines of personal interviewing and protection of human participants.
Each participating reservation/reserve provided a list of families of tribally enrolled children aged 10 to 12 years (with some minor variations due to birthdays from time of recruitment) who lived on or proximate to (within 50 miles) the reservation or reserve. We attempted to contact all families with a target child within the specified age range to achieve a population sample within participating communities of this cultural group. Families for this study were recruited through personal interviewer visits during which they were presented a traditional gift, an overview of the project, and an invitation to participate. For those families who agreed to participate, both the target adolescent and at least one adult caretaker (and in some cases, two adults) were interviewed and were given $\$ 40$ on completion of the interviews. Recruitment and incentive procedures were approved by both communitybased advisory boards and the university's institutional review board. The recruitment procedure resulted in an initial response rate of 79.4 percent. Retention rates ranged from 94.6 percent at Wave 2 to 90 percent at Wave 5 .

\section{Measures}

Aggression was assessed using the aggression subscale from the Diagnostic and Statistical Manual of Mental Disorders, fourth edition (American Psychiatric Association 1994), conduct disorder criteria. This measure is a summed count of six dichotomous indicators of aggressive behaviors at each wave of data collection. Adolescents were asked if they had done any of the following in the past 12 months: threatened or frightened someone on purpose, been in a physical fight in which someone was or could have been hurt, started a physical fight in which someone was or could have been hurt, tried to hurt someone badly or been physically cruel to someone, hurt someone with a weapon, and threatened someone with a weapon. Yes answers were coded as 1 , and no answers were coded as 0 . The measure had acceptable internal reliability at each wave, with Cronbach's $\alpha$ ranging from .71 at Wave 2 to .75 at Wave 5.

Perceived discrimination is a measure adapted from the Schedule of Racist Events (Landrine and Klonoff 1996) that has been validated in prior studies of Indigenous populations (Whitbeck et al. 2001). This measure is a mean indicator of the frequency of experiencing specific instances of discrimination. The adolescents were asked seven 


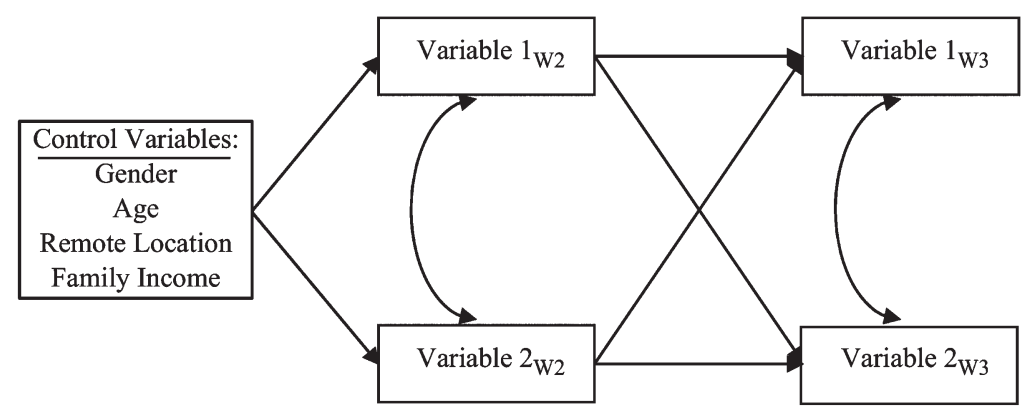

Figure 2. Autoregressive cross-lag model

questions regarding how often in the past 12 months the following experiences occurred because of their ethnicity: other kids have said something bad or insulting to you; a store owner, sales clerk, or person working at a place of business treated you in a disrespectful way; other kids ignored you or left you out of some activity; adults suspected you of doing something wrong; someone yelled a racial slur or racial insult at you; other kids treated you badly; and you had a teacher who didn't expect you to do well. Response options ranged from $0=$ never to $2=$ many times. Higher scores reflect more perceived discrimination. Cronbach's $\alpha$ for this scale was .83 at Wave 2, .80 at Wave 3 , and .81 at Wave 5.

Anger was assessed using the Tri-Ethnic Anger Scale (Oetting, Beauvais, and Edwards 1988). This measure is a mean indicator of the frequency of experiencing feelings of anger. The adolescents were asked six questions about how often they feel angry, are quick-tempered, get mad, feel like hitting someone, fly off the handle, or are hotheaded. Response options ranged from $0=$ none of the time to 2 = most of the time, with higher scores reflecting more anger. The measure has good internal reliability with Cronbach's $\alpha$ of .79 at Wave 2, .81 at Wave 3 , and .83 at Wave 5.

Control variables. Remote location refers to the proximity of the adolescent's reservation or reserve to towns or other communities. There are two locations identified for this sample. A rural location is within somewhat close proximity to other towns, and a remote location is far removed from other communities. All reservations and reserves are either rural or remote. The variable is coded so that $0=$ rural and $1=$ remote. Age is a continuous measure of the target adolescent's age on his or her last birthday at Wave 2. Gender is dichot- omized and coded such that $0=$ male and $1=f e-$ male. Per capita family income is measured by asking parents/caretakers to indicate their overall household incomes at Wave 2 as greater or less than $\$ 25,000$ in the past year. Two other questions narrow that response to $\$ 10,000$ to $\$ 15,000$ ranges. Midpoints of these ranges were divided by the number of people living within the household, which was then divided by 1,000 to set the metric of this measure in thousands of dollars.

\section{Method}

A series of autoregressive cross-lagged path models were tested to answer the first and second research questions regarding the temporal order of discrimination and aggression as well as anger and aggression. This type of model allows crossvariable associations to be measured after controlling for within-variable associations and also allows for reciprocal relationships to be tested (Burkholder and Harlow 2003). First, we tested a model for discrimination and aggression, which included autoregressive paths from aggression at Wave 2 (Aggression $_{\mathrm{W} 2}$ ) to aggression at Wave 3 $\left(\right.$ Aggression $\left._{\mathrm{W} 3}\right)$ as well as perceived discrimination at Wave 2 (Discrimination ${ }_{\mathrm{W} 2}$ ) to Wave 3 perceived discrimination (Discrimination $\mathrm{W}_{\mathrm{W}}$ ), plus cross-sectional correlations between the two constructs Aggression $_{\mathrm{W} 2}$ with Discrimination ${ }_{\mathrm{W} 2}$, Aggression $_{\mathrm{W} 3}$ with Discrimination $\left.\mathrm{W}_{3}\right)$. In addition, crosslag paths were added from discrimination to subsequent aggression and aggression to subsequent discrimination. We also control for age, gender, remote location, and per capita family income. We then tested a model for anger and aggression following the same procedure. The basic autoregressive cross-lag model is shown in Figure 2. 
To answer the third research question regarding the mediating role of anger, we use the results of the cross-lagged models to specify temporal order to estimate a path model of perceived discrimination and anger predicting later aggression. In this model, aggression at Wave 5 was added as a distal outcome of earlier discrimination and anger. We estimated cross-lagged paths from discrimination to anger and subsequent aggression, and from anger to subsequent aggression. As in the cross-lag models, autoregressive paths and cross-sectional correlations were included. Decomposition of effects was used to assess the indirect effects of early discrimination and anger on later aggression.

All autoregressive cross-lag model analyses were run with the Mplus structural equations program (Muthén and Muthén 2007). Results were interpreted in terms of the models' goodness of fit, using the following indices: the Tucker-Lewis Index, comparative fit index, and root mean square error of approximation. Values of greater than .90 are considered acceptable for the TuckerLewis Index and comparative fit index (Bentler 1990), and values of .05 to .08 for the root mean square error of approximation index reflect a satisfactory fit (Hu and Bentler 1999). Because two of the constructs (perceived discrimination and aggression) had positively skewed distributions, we used the maximum likelihood estimator with robust standard errors, which is robust to nonnormality (Asparouhov and Muthén 2005; Muthén and Muthén 2007).

The analyses are based on adolescent self-report data from Waves 2, 3, and 5, collected in 2003, 2004, and 2006. The baseline assessments of behaviors and experiences in the first wave of data collection used lifetime reports. In subsequent waves of full data collection (i.e., Waves 2, 3 , and 5), the reports were for behaviors and experiences in the past year. The fourth wave of data collection was limited to mental health diagnostic questionnaires and did not include the focal measures used in the present analysis. At Wave 2, target adolescents were between 11 and 14 years of age, with a mean age of 12 years. The sample is 50 percent female, 8.9 percent live on remote reserves, and the average per capita family income is $\$ 5,791$. Means, standard deviations, and alpha reliabilities for the study variables are presented at the bottom of Table 1 .

\section{Missing Data}

Over time, adolescents and their families left the study and in some cases reentered it. There were 707 adolescents interviewed in Wave 2, 695 in Wave 3, and 672 in Wave 5. Because we are estimating change over time, the analyses included only those adolescents for whom we had observations for at least two time points on the focal variables (discrimination, anger, and aggression). Maximum likelihood estimation with robust standard errors was used to handle missing data, a technique that maximizes statistical power by borrowing information from the observed data (Enders 2010). Of the 708 adolescents for whom we had at least two observations, 16 cases had missing data on all of the exogenous variables and were excluded from the analysis, resulting in a final sample size of 692 .

\section{Results}

\section{Univariate and Bivariate Analyses}

The mean number of aggressive behaviors increased from .75 aggressive acts in the past year at Wave 2 to .99 aggressive acts at Wave 5 (see the bottom of Table 1). Although the overall prevalence of aggressive behaviors was low (indeed, a large majority of adolescents at each wave reported engaging in no aggressive behavior), it did increase over time. The frequency of experiencing discrimination remained low over time, ranging from .21 to .26 . These values indicate that overall, adolescents reported experiencing discrimination never to a few times. Anger was higher than perceived discrimination but also remained steady over time, with values ranging from .94 to .97 . This translates to adolescents' feeling angry some of the time, on average.

Bivariate correlations (see the top of Table 1) indicate that discrimination, anger, and aggression are significantly associated with each other and that these associations occur across time. Significant positive associations were found among the focal variables at all three time points as well as across the time points. Discrimination ${ }_{\mathrm{W} 2}$ was correlated with anger and aggression at Waves 2, 3, and 5. Anger $_{\mathrm{W} 2}$ was also correlated with aggression at all three waves. But in general, associations between the more proximal variables (i.e., measured 


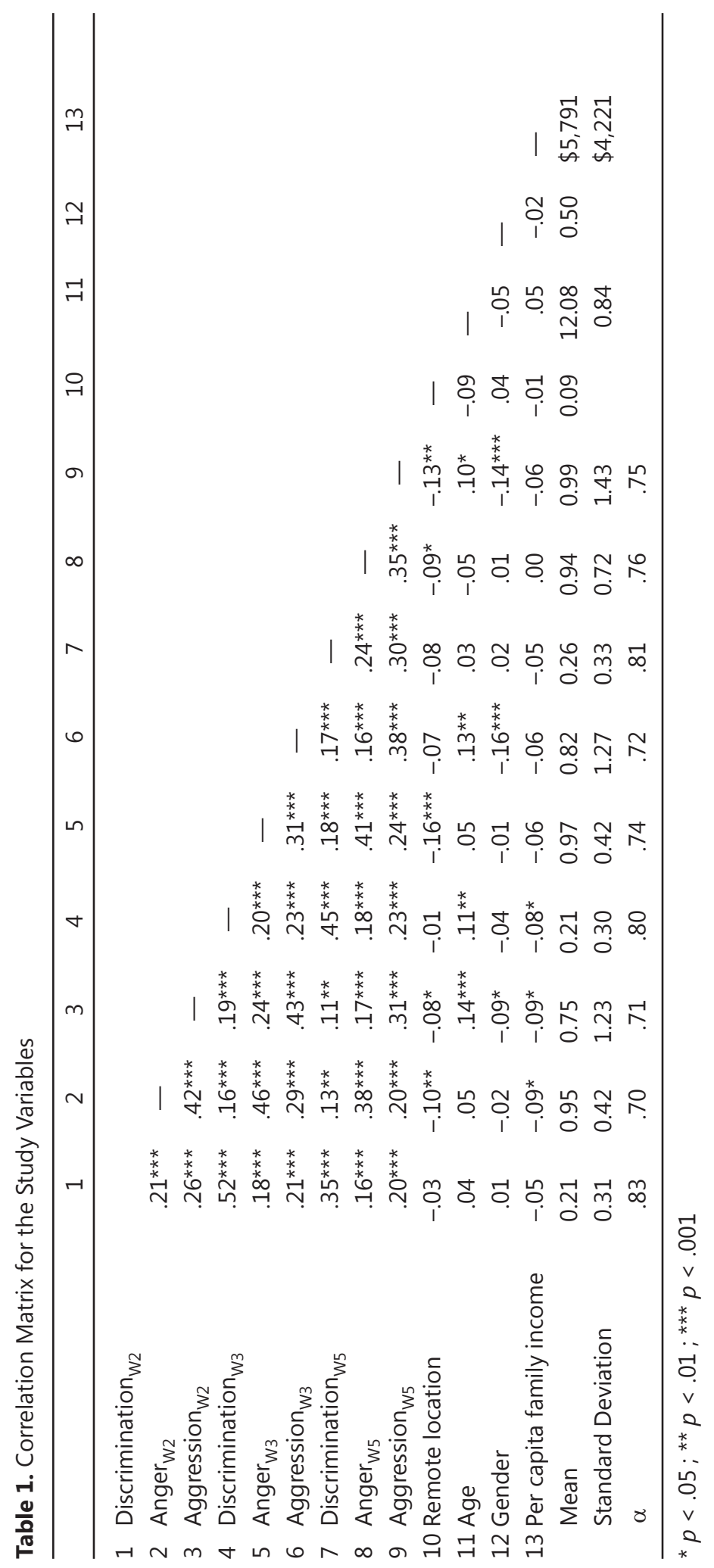


at the same time point) were stronger than those between distal variables. The strongest associations were between the same measures assessed at different time points (e.g., perceived discrimination at Waves 2, 3, and 5).

\section{Cross-lagged Path Models}

To address the first research question-Does early aggression increase perceived discrimination, or do experiences with discrimination lead to aggressive behavior? - a cross-lagged path model was estimated (see Table 2). To test for gender differences in the sequence of perceived discrimination and aggression, multigroup models were estimated. The multigroup model tests did not indicate any significant differences in parameters across models. Because there were no gender group differences, the model in which gender was included as a control variable was used. Overall model fit was adequate. Both aggression and discrimination were quite stable across time. The autoregressive paths were all strong and significant, suggesting good reliability and measurement of these constructs across time. The cross-sectional correlations were also significant and positive, ranging from .13 to .26 . The path from perceived discrimination to later aggression was significant and positive, even after controlling for prior aggression. There was no association between aggression and subsequent discrimination.

The second research question-Does aggressive behavior precede adolescent anger, or does anger lead to aggression? - was addressed using an autoregressive cross-lagged path model, presented in Table 2. As with the prior model, multigroup modeling was used to estimate possible gender differences in the temporal ordering of anger and aggression. Because the tests did not indicate significant differences across gender groups, we included gender as a control variable in the final model. This model had good fit. The autoregressive path for anger was strong, indicating that anger was quite stable across time. The cross-sectional correlations between anger and aggression were larger at both time points than those between discrimination and aggression. The association between Anger $_{\mathrm{W} 2}$ and Aggression ${ }_{\mathrm{W} 3}$ was significant and positive, even after controlling for earlier aggression. Most notably, the association between earlier aggression and later anger was not significant. To summarize the results of the two cross-lag path models, both perceived discrimination and anger were positively associated with later aggression, but aggression was not associated with either later discrimination or anger.

Path model of discrimination and anger on later aggression. Once the temporal order of the variables was identified, a path model was estimated, with earlier anger and perceived discrimination predicting later aggression (see Figure 3 and Table 3). Wave 5 aggression, perceived discrimination, and anger were added to the model. Because we did not test temporal ordering between perceived discrimination and anger, we included paths from anger to subsequent perceived discrimination and from perceived discrimination to subsequent anger. Based on the fit criteria described above, the path model had an acceptable fit. The variables in the model explained about 18 percent of variance in adolescent aggression at Wave 5. Perceived discrimination was positively associated with subsequent (i.e., in the next wave) aggression and anger. Anger was positively associated with subsequent aggression but was not associated with subsequent perceived discrimination.

To address the third research question regarding whether anger mediates the association between perceived discrimination and aggression, we examined the indirect effects of Perceived Discrimination ${ }_{\mathrm{W} 2}$ on Aggression $_{\mathrm{W} 5}$ (see Table 4). The significant indirect effect via anger was small but statistically significant, indicating that anger partially mediates the association between perceived discrimination at Wave 2 and aggression at Wave 5. We also calculated the total effects of perceived discrimination as well as the indirect and total effects of anger at Wave 2. (Direct effects from each of the Wave 2 variables on $_{\text {Aggression }}{ }_{\mathrm{W} 5}$ were tested, but neither the regression coefficients nor the chi-square test were significant; therefore, we did not include those paths in the final model.) Two interesting findings emerged. First, the effect of perceived discrimination at Wave 2 on aggression at Wave 5 was partially mediated by perceived discrimination at Wave 3. Furthermore, the total effect of Discrimination $_{\mathrm{W} 2}$ on Aggression $_{\mathrm{W} 5}$ was only slightly smaller in magnitude than the direct effect of perceived discrimination at Wave 3 on Aggression $_{\mathrm{W} 5}$. These results suggest that early experiences with perceived discrimination may be just as important as later experiences in understanding aggressive behavior. Second, the effect 


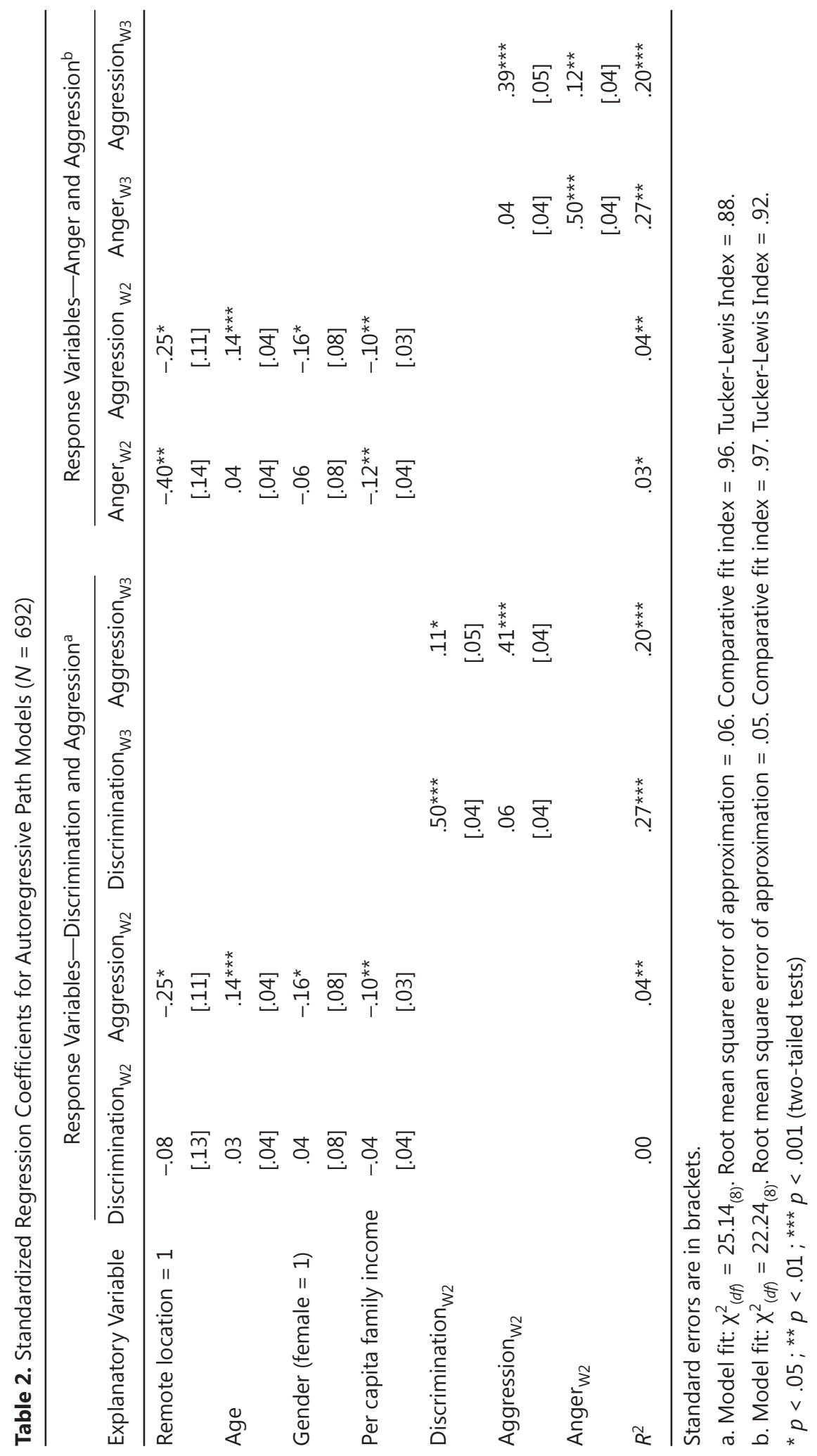




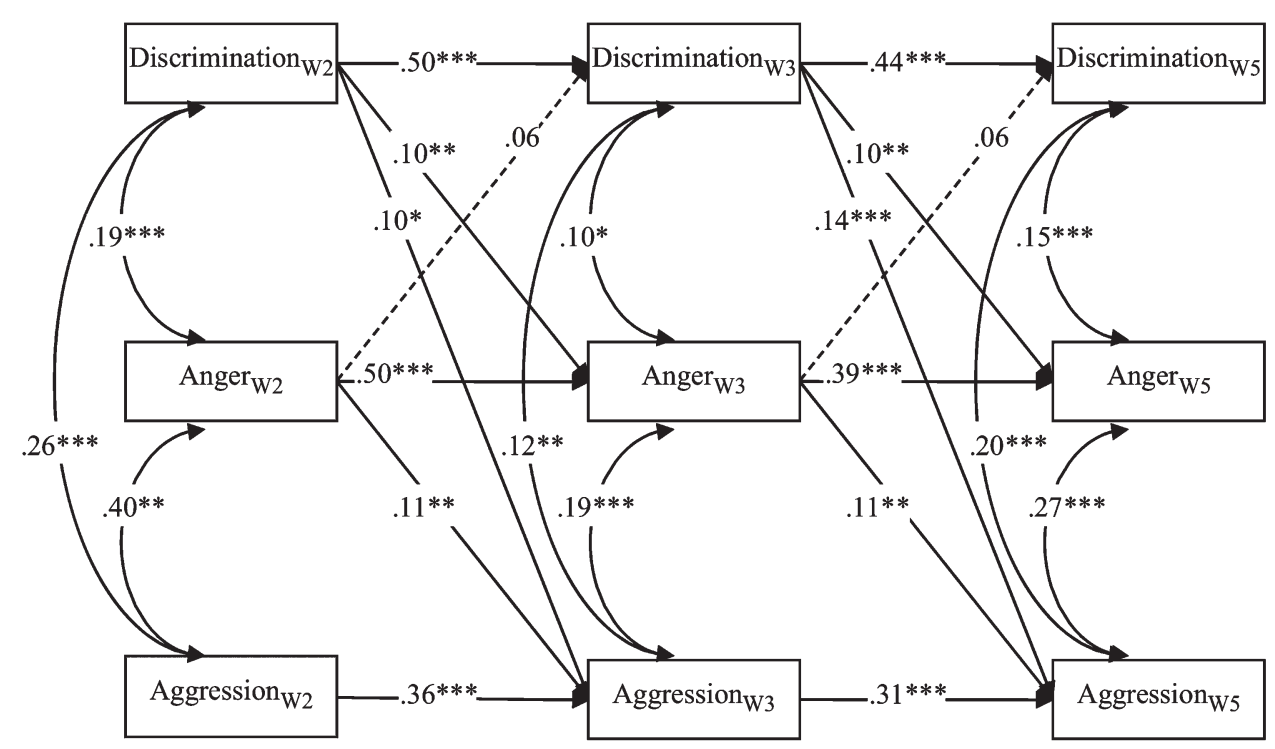

Figure 3. Path model of discrimination and anger on later aggression $(N=692)$. Controlling for age, gender, per capita family income, and remote location at Wave 2. $\chi^{2}{ }_{(d f)}=114.97_{(37)}$. Root mean square error of approximation $=.06$. Comparative fit index $=.93$. Tucker-Lewis Index $=.87$. Dashed lines indicate nonsignificant paths.

of Anger $_{\mathrm{W} 2}$ on Aggression ${ }_{\mathrm{W} 5}$ was partially mediated by anger at Wave 3, making the total effect of Anger $_{\mathrm{W} 2}$ on Aggression $_{\mathrm{W} 5}$ similar in magnitude to the direct effect of Anger $_{\text {W3 }}$ on Aggres$\operatorname{sion}_{\mathrm{W} 5}$. This indicates that early anger influences aggressive behavior both proximally and distally. In sum, early perceived discrimination and anger are each related to aggression three years later, and anger explains a portion of the perceived discrimination-aggression relationship.

\section{Discussion and Conclusions}

We could locate no prior studies with Indigenous youth that established the temporal order of perceived discrimination, anger, and aggression, nor any research that has investigated whether anger mediates the association between discrimination and aggression. Thus, these findings make three important contributions to the sociology of mental health. First, we established that perceived discrimination was significantly and positively associated with later aggression among Indigenous adolescents, even when controlling for prior aggression, age, gender, income, and location. Prior empirical work has found significant associations between perceived discrimination and a host of negative outcomes (e.g., Sellers et al. 2003; Whitbeck et al. 2001), but to our knowledge this is the first longitudinal analysis that orders the association between perceived discrimination and aggression across time and does so with a sample of Indigenous youth. This finding fits well within the stress paradigm in which perceived discrimination has been widely conceptualized as a stressor that negatively affects well-being (Harrell 2000; Williams et al. 2003; Williams et al. 1997).

Second, we tested the temporal order of anger and aggression and found that among this sample, anger was positively associated with changes in aggression. Prior research suggests that anger is a precursor to aggression (Aseltine et al. 2000; Camodeca and Goossens 2005; Cornell et al. 1999) but may also be a more common characteristic or reaction of aggressive children (Agnew et al. 2002; Smith et al. 1993). Our findings offer support for the first explanation, that among this sample of North American Indigenous youth, anger precedes aggressive behavior even when controlling for prior aggression, age, gender, income, and location.

Third, we found that anger partially mediates the perceived discrimination-aggression association. Early perceived discrimination (i.e., at Wave 2 when adolescents were ages 11 to 13 years) was 
Perceived Discrimination, Anger, and Aggression among Indigenous Adolescents

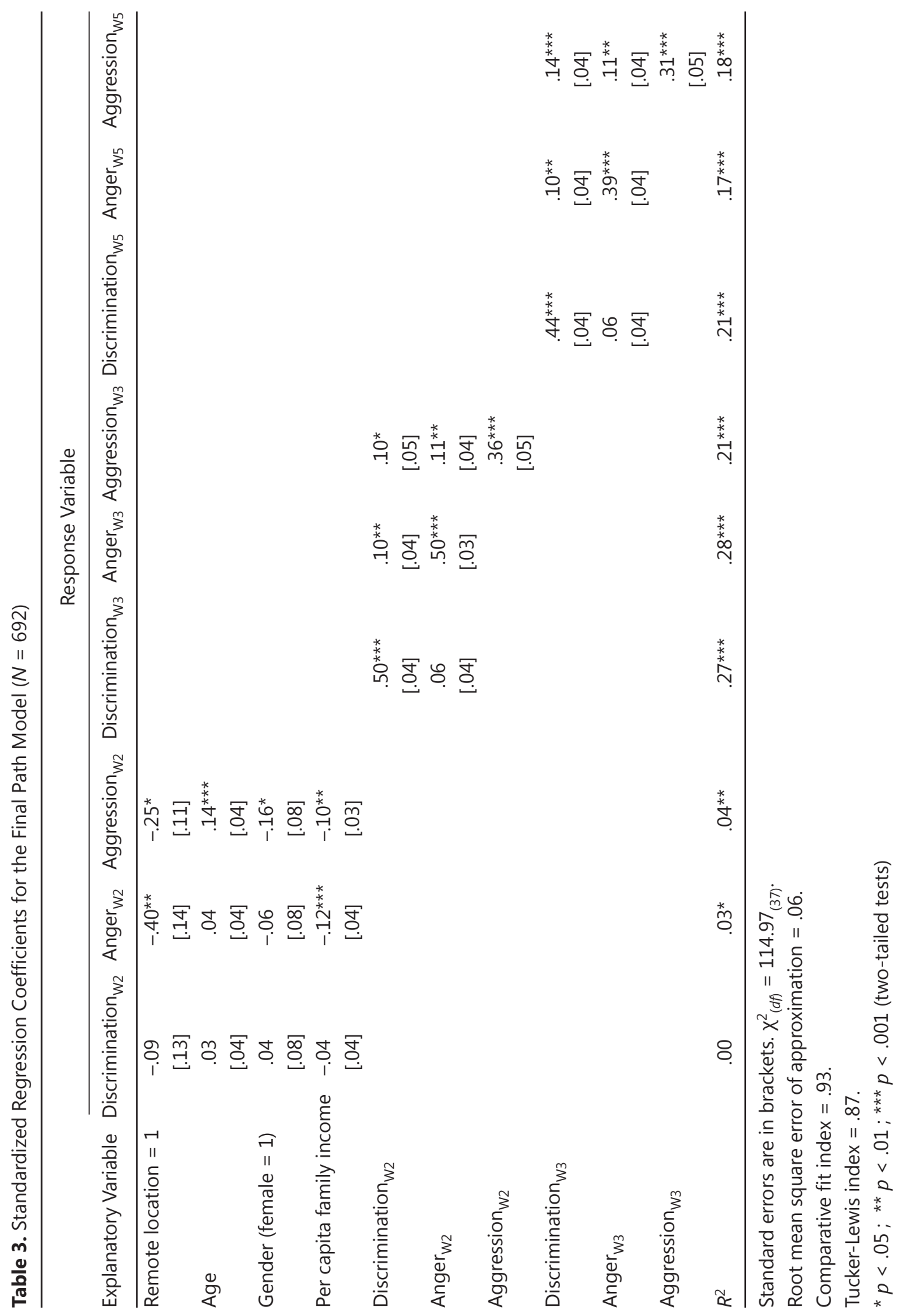


Table 4. Standardized Indirect and Total Effects of Discrimination, Anger, and Aggression at Wave 2 on Aggression at Wave 5

\begin{tabular}{|c|c|}
\hline & $\operatorname{ssion}_{W 5}$ \\
\hline \multicolumn{2}{|l|}{ Discrimination $_{\mathrm{W} 2}$} \\
\hline Indirect through Discrimination $_{\mathrm{W} 3}$ & $.07^{\star *}$ \\
\hline Indirect through Anger $_{\text {W3 }}$ & $.01^{*}$ \\
\hline Indirect through Aggression $_{\mathrm{W} 3}$ & .03 \\
\hline Total indirect effect & $.11^{* \star *}$ \\
\hline \multicolumn{2}{|l|}{ Anger $_{\text {w2 }}$} \\
\hline Indirect through Discrimination $_{\mathrm{W}_{3}}$ & .01 \\
\hline 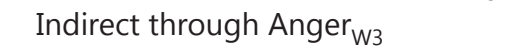 & $.06^{* \star}$ \\
\hline Indirect through Aggression $_{\mathrm{W} 3}$ & $.04^{* *}$ \\
\hline Total indirect effect & $.10^{* * *}$ \\
\hline
\end{tabular}

associated with aggressive behavior three years later via its effects on subsequent anger (i.e., at Wave 3). Furthermore, the effects of perceived discrimination may be cumulative. Perceived discrimination at Wave 2 was associated with aggression at Wave 5 via its effects on perceived discrimination at Wave 3 . These findings indicate that perceived discrimination has both more proximal, direct effects on aggression and distal effects, through anger and later perceived discrimination, that accumulate over time for these adolescents. Despite stability in perceived discrimination and anger, aggressive behavior increased among these Indigenous adolescents, suggesting that early experiences of perceived discrimination and the anger associated with them have longer-term consequences for aggressive behavior. The same pattern held for anger. A small but growing body of research has identified perceived discrimination as an important contributor to negative health and mental health outcomes for Indigenous people (e.g., Mellor et al. 2009; Walls et al. 2007; Whitbeck et al. 2001; Yoder et al. 2006). We expand on this literature by demonstrating perceived discrimination's effects on aggression as well as its indirect effects via anger and subsequent perceived discrimination for Indigenous youth.

This study provides further evidence of the detrimental effects of perceived discrimination on adolescent well-being and does so with an under- studied population of North American Indigenous adolescents. The life courses of different racial and ethnic groups are "products of not only their specific individual experiences but also their membership in historically distinct and unequal social and economic groupings" (Hawkins, Laub, and Lauristen 1998:40). Following Wheaton and Clarke's (2003) argument that past social contexts are important to present functioning, we posit that current social contexts are important to future functioning and well-being.

The present study offers important insights for crime and delinquency scholars as well. Perceived discrimination has been notably absent from criminological explanations of aggressive and delinquent behaviors (Unnever et al. 2009). Trying to explain differences in crime and delinquency for minority groups, and in particular for Indigenous youth, by looking only at individual-level explanatory factors and excluding social and historical contexts will give an incomplete picture. Perceived discrimination is a significant source of strain for minority adolescents that affects negative emotional responses such as anger, both of which are important in understanding why some Indigenous adolescents engage in aggressive behavior. Although not the only explanatory factors, perceived discrimination and anger do serve to situate the behavior in both contemporary and historical contexts.

\section{Limitations}

As with all research, this study has limitations that need to be considered. First, although this is a prospective longitudinal study, only three waves of data were available for this analysis. Replicating this study as the adolescents age into adulthood will enrich our understanding of the developmental and potentially cumulative effects of discrimination and anger on aggressive behavior. Second, although we were able to establish the temporal order of the variables, we do not claim that discrimination or anger causes adolescents to become aggressive. By accounting for prior levels of aggression, however, perceived discrimination and anger are each positively associated with changes in aggression and likely contribute to the development of aggression during adolescence. Future research on younger respondents that measures discrimination, anger, and aggression, as well as alternative explanations for aggression, is neces- 
sary to better understand the contributions of perceived discrimination and anger to the etiology of aggression. Third, these results may not be generalizable to different Indigenous cultures. The diversity of Indigenous cultures within the United States and Canada is substantial, and the patterns and findings of this study may not apply to other cultures. Fourth, this sample is entirely rural and may not reflect experiences of urban Indigenous adolescents. Even with these limitations in mind, we believe that the findings of this study contribute to the overall literatures on aggression and perceived discrimination, particularly as they apply to minority adolescents.

\section{Conclusions}

This research lays the foundation for further longitudinal studies pertaining to the effects of perceived discrimination on the development of young people. It is very clear from these analyses that discrimination experiences contribute to the etiology of anger and aggressive behaviors among Indigenous adolescents. It is likely that this same pattern will hold for the effects of other negative developmental outcomes such as psychological distress and substance abuse. The issue of timing is extremely important. Many adolescents may experience discrimination for the first time in their teenage years, yet others may have even earlier experiences. Emerging research on childhood stress suggests that early adversity such as discrimination contributes to health, mental health, and behavioral disparities across the life course as well as the intergenerational transmission of disparities (Shonkoff et al. 2012). As Pearlin and colleagues (2005:209) note, "early adversity in an important domain of life can be connected to later health when that adversity has a presence that reaches across time." There is a need for further research in Indigenous communities that will enhance our understanding of the effects of perceived discrimination, as well as the mechanisms through which they function, on the well-being of Indigenous people over the life course.

As evidence mounts that discrimination is an important stressor for minority adults and adolescents, it is critical that we develop early responses to ameliorate its effects. These could involve family-based programs wherein families are taught to develop action plans to deal with discrimination assertively rather than trying to cope passively or to lash out. School-based programs should do more than demonstrate that discrimination exists; they need to teach skills for dealing with the associated anger and the potential for acting on it. Finally, we need efforts at the macro level to address structural inequalities to "lessen people's lifetime accruals of events and chronic hardships" (Thoits 2010:S47). Perceived discrimination is but one of many strains related to the unequal social position that these reservation-dwelling Indigenous youth experience. North American Indigenous people also face frequent reminders of the historical losses their people have suffered, including ethnic cleansing, boarding schools, and forced relocation to reservations and reserves (Duran and Duran 1995; Whitbeck et al. 2004). With few economic and educational opportunities and high rates of poverty (Ogunwole 2006), many reservations resemble Third World countries. As Thoits (2010) notes in her review of stress research, the stressors of minority group status, including discrimination, are additive in their harmful effects on well-being and contribute to the proliferation of disparities across generations. As the present study demonstrates, the accumulation of perceived discrimination experiences and its effects on anger has long-term consequences for aggression among Indigenous youth.

Acknowledgments - This research was funded by the National Institute on Drug Abuse (DA13580) and the National Institute of Mental Health (MH67281) (Les B. Whitbeck, principal investigator).

\section{References}

Agnew, Robert. 1992. "Foundation for a General Strain Theory of Crime and Delinquency." Criminology 30(1):47-88.

Agnew, Robert. 2001. "Building on the Foundation of General Strain Theory: Specifying the Types of Strain Most Likely to Lead to Crime and Delinquency." Journal of Research in Crime and Delinquency 38(4):319-61.

Agnew, Robert, Timothy Brezina, John Paul Wright, and Francis T. Cullen. 2002. "Strain, Personality Traits, and Delinquency: Extending General Strain Theory." Criminology 40(1):43-72.

American Psychiatric Association. 1994. Diagnostic and Statistical Manual of Mental Disorders. 4th ed. Washington, DC: American Psychiatric Association. 
Aseltine, Robert H., Susan Gore, and Jennifer Gordon. 2000. "Life Stress, Anger and Anxiety, and Delinquency: An Empirical Test of General Strain Theory." Journal of Health and Social Behavior 41(3):256-75.

Asparouhov, Tihomir and Bengt Muthén. 2005. "Multivariate Statistical Modeling with Survey Data." Proceedings of the Federal Committee on Statistical Methodology (FCSM) Research Conference. Retrieved July 11, 2011, from http://www.fcsm.gov/05papers/Asparouhov Muthen IIA.pdf

Bachman, Ronet. 1992. Death and Violence on the Reservation: Homicide, Family Violence, and Suicide in American Indian Populations. New York: Auburn House.

Bentler, Peter M. 1990. "Comparative Fit Indexes in Structural Models." Psychological Bulletin 107(2): 238-46.

Berkowitz, Leonard and Eddie Harmon-Jones. 2004. "Toward an Understanding of the Determinants of Anger." Emotion 4(2):107-30.

Brezina, Timothy. 1996. "Adapting to Strain: An Examination of Delinquent Coping Responses." Criminology 34:39-60.

Burkholder, Gary J. and Lisa L. Harlow. 2003. "An Illustration of a Longitudinal Cross-lagged Design for Larger Structural Equation Models." Structural Equation Modeling 10(3):465-86.

Caldwell, Cleopatra H., Laura P. Kohn-Wood, Karen H. Schmeelk-Cone, Tabbye M. Chavous, and Marc A. Zimmerman. 2004. "Racial Discrimination and Racial Identity as Risk or Protective Factors for Violent Behaviors in African American Young Adults." American Journal of Community Psychology 33(1):91-105.

Camodeca, Marina and Frits A. Goossens. 2005. “Aggression, Social Cognitions, Anger and Sadness in Bullies and Victims." Journal of Child Psychology and Psychiatry 46(2):186-97.

Cornell, Dewey G., Catherine S. Peterson, and Herbert Richards. 1999. "Anger as a Predictor of Aggression among Incarcerated Adolescents." Journal of Consulting and Clinical Psychology 67(1):108-15.

Crick, Nicki R. and Kenneth A. Dodge. 1996. "Social Information-processing Mechanisms in Reactive and Proactive Aggression." Child Development 67(3):993-1002.

Crocker, Jennifer, Kristin Voelkl, Maria Testa, and Brenda Major. 1991. "Social Stigma: The Affective Consequences of Attributional Ambiguity." Journal of Personality and Social Psychology 60(2):218-28.

Dodge, Kenneth A., Jennifer E. Lansford, Virginia Salzer Burks, John E. Bates, Gregory S. Pettit, Reid Fontaine, and Joseph M. Price. 2003. "Peer Rejection and Social Information-processing Factors in the Development of Aggressive Behavior Problems in Children." Child Development 74(2): 374-93.

Duran, Eduardo and Bonnie Duran. 1995. Native American Postcolonial Psychology. Albany: State University of New York Press.

Enders, Craig K. 2010. Applied Missing Data Analysis.
New York: Guilford.

Greenfeld, Lawrence A. and Steven K. Smith. 1999. American Indians and Crime. Washington, DC: Bureau of Justice Statistics.

Harrell, Shelly P. 2000. "A Multidimensional Conceptualization of Racism-related Stress: Implications for the Well-being of People of Color. "American Journal of Orthopsychiatry 70(1):42-57.

Hawkins, Darnell F., John H. Laub, and Janet L. Lauristen. 1998. "Race, Ethnicity, and Serious Juvenile Offending." Pp. 30-46 in Serious and Violent Juvenile Offenders: Risk Factors and Successful Interventions, edited by R. Loeber and D. P. Farrington. Thousand Oaks, CA: Sage.

Hoffmann, John P. 2010. "A Life-course Perspective on Stress, Delinquency, and Young Adult Crime." American Journal of Criminal Justice 35(3): 105-20.

Hoffmann, John P. and Felicia Gray Cerbone. 1999. "Stressful Life Events and Delinquency Escalation in Early Adolescence." Criminology 37(2): 343-74.

$\mathrm{Hu}$, Li-tze and Peter M. Bentler. 1999. "Cutoff Criteria for Fit Indexes in Covariance Structure Analysis: Conventional Criteria versus New Alternatives." Structural Equation Modeling 6(1):1-55.

Kessler, Ronald C., Kristin D. Mickelson, and David R. Williams. 1999. "The Prevalence, Distribution, and Mental Health Correlates of Perceived Discrimination in the United States." Journal of Health and Social Behavior 40(3):208-30.

Landrine, Hope and Elizabeth A. Klonoff. 1996. “The Schedule of Racist Events: A Measure of Racial Discrimination and a Study of Its Negative Physical and Mental Health Consequences." Journal of Black Psychology 22(2):144-68.

Martin, Monica J., Bill McCarthy, Rand D. Conger, Frederick X. Gibbons, Ronald L. Simons, Carolyn E. Cutrona, and Gene H. Brody. 2011. "The Enduring Significance of Racism: Discrimination and Delinquency among Black American Youth." Journal of Research on Adolescence 21:662-76.

Mellor, David, María Eugenia Merino, José L. Saiz, and Daniel Quilaqueo. 2009. “Emotional Reactions, Coping and Long-term Consequences of Perceived Discrimination among the Mapuche People of Chile." Journal of Community \& Applied Social Psychology 19(6):473-91.

Meyer, Ilan H. 1995. "Minority Stress and Mental Health in Gay Men." Journal of Health and Social Behavior 36(1):38-56.

Muthén, Linda K. and Bengt O. Muthén. 2007. Mplus User's Guide. 5th ed. Los Angeles: Muthén \& Muthén.

Oetting, Eugene R., Fred Beauvais, and Ruth Edwards. 1988. "Alcohol and Indian Youth: Social and Psychological Correlates and Prevention." Journal of Drug Issues $18(1): 87-101$.

Ogunwole, Stella U. 2006. We the People: American Indians and Alaska Natives in the United States. U. S. Census Bureau, U.S. Department of Commerce. 
Patterson, Gerald R., Barbara D. DeBaryshe, and Elizabeth Ramsey. 1989. "A Developmental Perspective on Antisocial Behavior." American Psychologist 44(2):329-35.

Pearlin, Leonard I. 1999. "Stress and Mental Health: A Conceptual Overview." Pp. 161-75 in A Handbook for the Study of Mental Health: Social Contexts, Theories, and Systems, edited by A. V. Horwitz and T. L. Schied. Cambridge, UK: Cambridge University Press.

Pearlin, Leonard I., Scott Schieman, Elena M. Fazio, and Stephen C. Meersman. 2005. "Stress, Health, and the Life Course: Some Conceptual Perspectives." Journal of Health and Social Behavior 46(2):205-19.

Perry, Steven W. 2004. American Indians and CrimeA BJS Statistical Profile, 1992-2002. Washington, DC: U.S. Department of Justice, Bureau of Justice Statistics.

Royal Commission on Aboriginal Peoples. 1996. "Highlights from the Report of the Royal Commission on Aboriginal Peoples." Indian and Northern Affairs Canada. Retrieved July 2, 2010, from http://www.aincinac.gc.ca/ap/pubs/rpt/rpt-eng.asp

Sellers, Robert M., Cleopatra H. Caldwell, Karen H. Schmeelk-Cone, and Marc A. Zimmerman. 2003. "Racial Identity, Racial Discrimination, Perceived Stress, and Psychological Distress among African American Young Adults." Journal of Health and Social Behavior 44(3):302-17.

Shonkoff, Jack P., Andrew S. Garner, The Committee on Psychosocial Aspects of Child and Family Health, The Committee on Early Childhood, Adoption, and Dependent Care, and The Section on Developmental and Behavioral Pediatrics. 2012. "The Lifelong Effects of Early Childhood Adversity and Toxic Stress." Pediatrics 129:e232-46.

Smith, Craig A., Kelly N. Haynes, Richard S. Lazarus, and Lois K. Pope. 1993. "In Search of the 'Hot' Cognitions: Attributions, Appraisals, and Their Relation to Emotion." Journal of Personality and Social Psychology 65(5):916-29.

Taylor, John and R. Jay Turner. 2002. "Perceived Discrimination, Social Stress, and Depression in the Transition to Adulthood: Racial Contrasts." Social Psychology Quarterly 65(3):213-25.

Thoits, Peggy A. 2010. "Stress and Health." Journal of Health and Social Behavior 51(1 suppl.):S41-53.

Unnever, James D., Francis T. Cullen, Scott A. Mathers, Timothy E. McClure, and Marisa C. Allison. 2009. "Racial Discrimination and Hirschi's Criminological Classic: A Chapter in the Sociology of Knowledge." Justice Quarterly 26(3):377-409.

Vega, William A. and Rubén G. Rumbaut. 1991. “Ethnic Minorities and Mental Health." Annual Review of Sociology 17:351-83.

Walls, Melissa L., Les B. Whitbeck, Dan R. Hoyt, and Kurt D. Johnson. 2007. "Early-onset Alcohol Use among Native American Youth: Examining Female
Caretaker Influence." Journal of Marriage and Family 69(2):451-64.

Wheaton, Blair. 1994. "Sampling the Stress Universe." Pp. 77-114 in Stress and Mental Health: Contemporary Issues and Prospects for the Future, edited by W. R. Avison and I. H. Gotlib. New York: Plenum.

Wheaton, Blair and Philippa Clarke. 2003. "Space Meets Time: Integrating Temporal and Contextual Influences on Mental Health in Early Adulthood." American Sociological Review 68(5):680-706.

Whitbeck, Les B., Xiaojin Chen, Dan R. Hoyt, and Gary W. Adams. 2004. “Discrimination, Historical Loss and Enculturation: Culturally Specific Risk and Resiliency Factors for Alcohol Abuse among American Indians." Journal of Studies on Alcohol 65(4):409-18.

Whitbeck, Les B., Dan R. Hoyt, Xiaojin Chen, and Jerry D. Stubben. 2002. "Predictors of Gang Involvement among American Indian Adolescents." Journal of Gang Research 10(1):11-26.

Whitbeck, Les B., Dan R. Hoyt, Barbara J. McMorris, Xiaojin Chen, and Jerry D. Stubben. 2001. "Perceived Discrimination and Early Substance Abuse among American Indian Children." Journal of Health and Social Behavior 42(4):405-24.

Whitbeck, Les B., Barbara J. McMorris, Dan R. Hoyt, Jerry D. Stubben, and Teresa D. LaFromboise. 2002. "Perceived Discrimination, Traditional Practices, and Depressive Symptoms among American Indians in the Upper Midwest." Journal of Health and Social Behavior 43(4):400-18.

Williams, David R., Harold W. Neighbors, and James S. Jackson. 2003. "Racial/Ethnic Discrimination and Health: Findings from Community Studies." American Journal of Public Health 98(Suppl. 1): S29-37.

Williams, David R., David T. Takeuchi, and Russell K. Adair. 1992. "Socioeconomic Status and Psychiatric Disorder among Blacks and Whites." Social Forces 71(1):179-94.

Williams, David R., Yan Yu, James S. Jackson, and Norman B. Anderson. 1997. "Racial Differences in Physical and Mental Health: Socio-economic Status, Stress and Discrimination." Journal of Health Psychology 2(3):335-51.

Yoder, Kevin A., Les B. Whitbeck, Dan R. Hoyt, and Teresa D. LaFromboise. 2006. "Suicidal Ideation among American Indian Youths." Archives of Suicide Research 10(2):177-90.

Zimmerman, Marc A., Jesus Ramierex-Valles, Kathleen M. Wahienko, Benjamin Walter, and Sandra Dyer. 1996. “Enculturation Hypothesis: Exploring Direct and Protective Factors among Native American Youth." Pp. 199-219 in Resiliency in Ethnic Minority Families. Vol. 1, Native and Immigrant American Families, edited by H. I. McCubbin, E. A. Thompson, A. I. Thompson, and J. E. Fromer. Madison: University of Wisconsin. 